\title{
Developments in Plasma Arc Cutting (PAC) of Steel Alloys: A Review
}

\author{
(Pembangunan dalam Pemotongan Arka Plasma (PAC) AloiBesi: Ulasan) \\ Zeki Cinar, Mohammed. Asmael*, Qasim. Zeeshan \\ Department of Mechanical Engineering, Eastern Mediterranean University, North Cyprus, Turkey
}

\section{ABSTRACT}

The Plasma Arc Cutting (PAC) process was developed for difficult-to-machine materials in order to overcome the inefficiency and ineffectiveness of conventional machining methods when it comes to complex shapes and tool wear due to the contact between the tool and the workpiece. PAC consumes ionized gas, known as the heat source, and a high energy stream, known as the plasma. Many researchers have examined the PAC of steel alloys by considering the cutting power, scanning speed, cutting height and plasma gas pressure as the process parameters, and analysing the effects on the edge roughness, the kerf taper angle (conicity), burr formation, Heat Affected Zone (HAZ), Material Removal Rate (MRR), surface quality after cutting, and the metallurgical effects of the cut. A comprehensive review was carried out on developments in the analysis and optimization of PAC for steel alloys. It is observed that, the feed rate and edge roughness have a significant effect on the machining characteristics; however, less consideration was given by the researcher to these parameters. In addition, a critical comparison was made of the process parameters involved and the methods of analysis used, with the aim of providing the status of current research and guidance for future research.

Keywords: Plasma Arc Cutting (PAC), Heat Affected Zone (HAZ), Material Removal Rate (MRR), Steel alloys, Design of Experiments (DOE).

\section{INTRODUCTION}

Plasma Arc Cutting (PAC) is a non-conventional process which can perform several electrically conducting materials, stainless steel, aluminum and its alloys, magnesium, titanium alloys, manganese steel and cast iron. Plasma cutting process is invented about 30 years ago for processing hard and difficult to machine materials. The aim of the study is to gather different studies from the published papers to highlight which studies are carried out about plasma arc cutting machine.

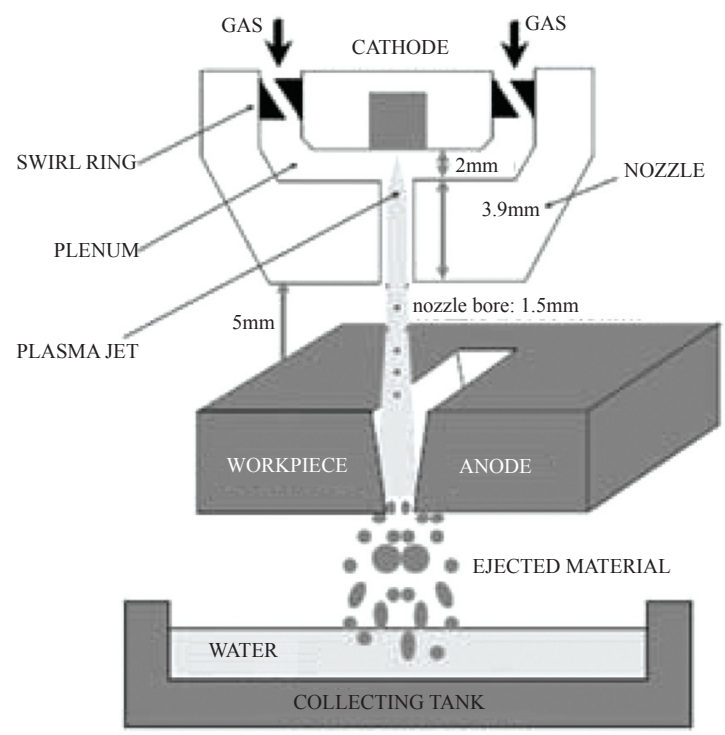

FIGURE1. Principle of PAC (Ramakrishnan et al.(2000))
Principle of the PAC is shown in Figure 1. Salonitis et al. (2012) observed that nitrogen or argon-hydrogen combination is used as plasma gas for cutting process. The plasma is additionally supported by a water cooled nozzle and its density can reach up to $2 \times 10^{6} \mathrm{~W} / \mathrm{cm}^{2}$ inside the plasma beam. Due to the high temperature, plasma expands and flows with supersonic velocity speed from nozzle to the work-piece. Inside the plasma arc, temperature can rise up to $30,000{ }^{\circ} \mathrm{C}$. Temperature can be adjusted relatively to material thickness and cutting speeds of electrically conductive materials. The stability of the arc is prior for the desirable performances.

\section{PAC PROCESS PARAMETERS}

PAC process parameters are studied in several papers such as Ramakrishnan et al. (2000), Xu et al. (2002), Zajac et al. (2006), Teulet et al. (2006), Ilii et al. (2010), Wang et al. (2011) and Klimpe et al. (2017). Some major investigations are also conducted to study with their effects on machining. The parameters affecting plasma is presented as shown by Salonitis et al. (2012):

1. Shape of plasma torch

2. Streaming jet

3. Water.

Parameters required to be monitored during process:

1. Temperature and electrical conducting

2. Density of plasma jet

3. Diameter of plasma beam 
4. Degree of the plasma beam focusing in output from nozzle.

Also dominant parameters for cutting process are presented as following.

1. Cutting speed

2. Cutting current

3. Cutting height or standoff

4. Nature, pressure and flow of the plasma gas.

For the cutting process, firstly a pilot arc ignition by a high voltage between nozzle and cathode takes place. Low energy pilot arc is then being prepared by the ionization between plasma torch and work-piece. Nemchinsky et al. (2006) mentioned that if the pilot arc touches the work-piece, then main arc will take place by an automatic increase in the power.

Introduction of air utilized as plasma gas first time in 1964. Cutting process with the help of gas is done by nozzle which is presented in Figure 2. Introduction of the air permitted to increase cutting speed while enhancing the cut quality severely. Due to the faster erosion of the electrode, zirconium cathode is preferred for the process rather than tungsten cathode utilization in which air is used as plasma gas.

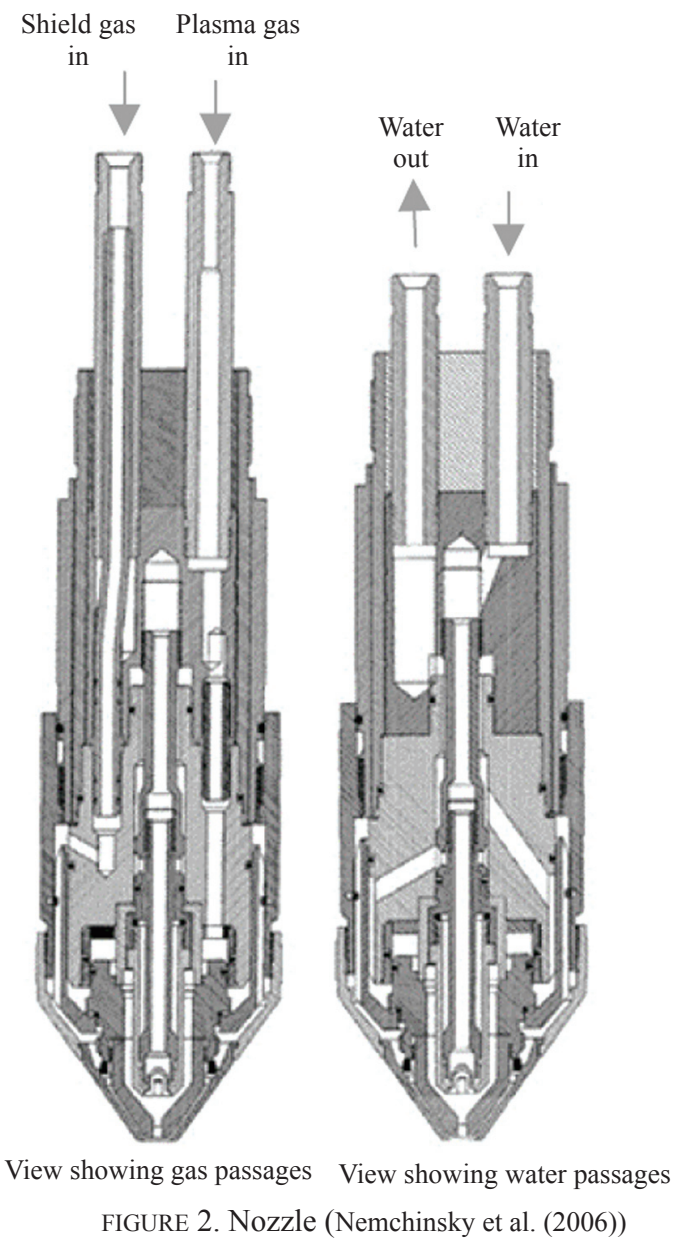

Introduction of nitrogen (N2) water-injection plasma arc torches utilized first time in 1970. Simple principle of the process can be explained as: injection of 1 or $2 \mathrm{~L} / \mathrm{min}$ of water into the arc and almost half of the injected water is utilized for either disassociated or evaporated by the arc. This process allows producing enormously square cuts without rounding at the top.

Introduction of oxygen water-injection plasma was invented in the early 1980s and thus enhancements are taken place in cut quality for mild plate's thickness of $25 \mathrm{~mm}$ or less. Low amplitude oscillation component of the arc current (current ripple) caused substantial increase in the erosion rate of the electrode. This invention affected current ripple to supply less power, thus electrolyte lifespan is enhanced as well as electrode and nozzle lifespan is increased due to the elimination of current overshoot and sloping.

Introduction of the hafnium insert electrode which lasts approximately 1.5 times longer than the zirconium insert cathode is invented during the 1980s. Today's most common plasma arc cutting electrodes made of hafnium insert electrode. This electrode can perform up to 100A current for the systems air cooling is supported, whereas it can serve up to $400 \mathrm{~A}$ for the systems liquid cooling supported.

Double arching is the phenomena that limit the capability of the PAC process. In normal operations, the nozzle is in neutral, so there is no electrical connection to any part of the circuit. However, for the double arching, the arc is connected to work and the nozzle. Therefore, catastrophic damage of the nozzle and cathode occurs. During the double arching, there are specific conditions to be hold. Nemchinsky et al. (2006) show the conditions as follows:

1. The arc current is too high, and/or

2. The nozzle orifice is too narrow, and/or

3. The nozzle orifice is too long, and/or

4. The gas flow is too low, and/or

5. The gas flow does not have enough swirl.

Dual gas torches are introduced first time in the 1960 and Gasses termed as 'secondary' and 'shielding' gas. The noble reason of dual gas utilization is to enhance cut quality and to protect the torch during the piercing process. Dual gasses are then enhanced to produce "precision" plasma systems (very tight constricted arc jet) which are capable of competing with the laser in some applications. After the inventions of the specific parameters, PAC is an influential industrial non-conventional system and capable of cutting various materials with high productivity. Applications can be consisted of 2 types, one is the light manual systems designed for small drops that requires less current such as $100 \mathrm{~A}$ and other is powerful systems designed for $\mathrm{CNC}$ machining that requires higher currents such as $400 \mathrm{~A}$.

A hypothesis base on arc-on erosion conditions was proposed and discussed by Salonitis et al. (2012) and Nemchinsky et al. (2003). The arc-on erosion is connected to the removal of insulating layer of hafnium oxide. The slow increase in arc current during the switching arc causes decrease in arc-on erosion. Ones arc switching is performed; 
the pilot arc between electrode and the nozzle is kindled. Firstly, the arc is recognized at the edge of the holder and then moved to the center of the emitter.

For the hypothesis base on the arc-off erosion, optical observations of the arc chamber through a small hole in the nozzle studied in Peters et al. (2005). It is discovered that small droplets are encountered in the chamber during arc quenching. Peters et al. (2005) had observed that presence of the droplets is based on the complex interaction between the pressurized flows of plasma through the nozzle also, Nemchinsky et al. (2003) studied the complex interaction between the molten surfaces of the electrode.

Previously studied topics by the researchers are gathered in this paper to create a timeline of the plasma arc cutting machine in the literature. Specially studied topics about PAC and combination of one or more than one details related to PAC reviewed and major investigations are stated in this paper. Although many topics are explained in the articles and conference papers, simplified information from each paper is collected and conducted to study to find out what can be studied more about PAC.

Zajac et al. (1995) proposed weight measurement of the AISI 1017 mild steel specimens. MRR based on the proposed material is carried out for the PAC process. Zajac et al. (1995) used the calculation for material removal rate (MRR) calculation mentioned in Eq. 1.

$$
M R R=(\text { Weight diff/density }) / \text { Cutting time }
$$

\section{DESIGN \& ANALYSIS METHODS}

Design of experiments (DOE) is a family of structured, organized techniques used to empirically understand the impact of process parameters (variables or factors) on the process performance and assist in identifying the optimum variables values. The main advantage of these techniques is ability to provide results with only a fraction of all the possible experimental combinations. Yang et al. (2001), Zajac et al. (2006), Bini et al. (2008), Radovanovic et al. (2011), Mis et al. (2011), Bhuvenesh et al. (2012), Salonitis et al. (2012), Das et al. (2014), Prajapati (2015), Kechagias et al. (2017) and Klimpel et al. (2017) are conducted DOE technique to find optimal solution for the specified parameters.

Taguchi is an engineering method for product design that focuses on minimizing variation and or sensitivity to noise. When used properly, Taguchi design provides a powerful and efficient method for designing products that operate consistently and optimally over a variety of conditions. In robust parameter design the primary goal is to find factors setting that minimize the response variation, while adjusting (or keeping) the process on target. After determine which factors affect about variation, the fine settings for controllable factors will be possible to achieve. These factors that will either reduce the variation, make the product insensitive to changes in uncontrollable (noise) factors, or both, a process designed with goal will produce more consistent output. Moreover, the product designed with this goal will deliver more consistent performance regardless of the environment in which it is used. Yang et al. (2001), Bini et al. (2008), Radovanovic et al. (2011), Mis et al. (2011), Bhuvenesh et al. (2012), Salonitis et al. (2012), Das et al. (2014), Prajapati (2015) and Kechagias et al. (2017) are conducted this technique to their study.

Analysis of variance (ANOVA) is a statistical model which can be used for find out effect of independent parameter on single dependent parameter and also it can be useful to find out the significant machining parameters and the percentage contribution of each parameter. ANOVA is used to check the sufficiency of the second order model which includes test for significance of regression model, model coefficients and test for lack of fit. Yang et al. (2001), Mis et al. (2011), Cebeli et al. (2012), Das et al. (2014), Prajapati (2015), Kechagias et al. (2017) and Balaganesh et al. (2017) conducted this method to their study.

Fuzzy Logic (FL) is a method of reasoning that resembles human reasoning. The approach of FL imitates the way of decision making in humans that involves all intermediate possibilities between digital values YES and NO. For instance, it is used to combine all machining process parameters for PAC and then creates intermediate possibilities of the combination to reach best result. Cebeli et al. (2012) conducted this technique to their study.

Ramakrishnan et al. (2000) investigated the influence of the plasma gas composition (oxygen, nitrogen and air) on the plasma cutting process. Results of kerf width, leading edge of cut front and arc voltage have been obtained from experiments performed by cutting $6 \mathrm{~mm}$ mild steel plates at different cutting speeds $(1,2$ and $3 \mathrm{~m} / \mathrm{min})$ with a $100 \mathrm{~A}$ plasma torch operating with approximately the same mass flow rates of nitrogen, air and oxygen as plasma gases. The upper limit for the speed of cutting increases with the presence of oxygen in the plasma gas by the measured values of 2.5, 4.7 and $4.2 \mathrm{~m} / \mathrm{min}^{-1}$, respectively, for nitrogen, air and oxygen. An approximate energy balance has been made for all the three chosen plasma gases at different speeds by estimating the available thermal energy from the plasma, the likely maximum energy released by oxidation, and the energy required to melt material from measured kerfs. A comparison of the energy balance for different gases shows that the energy that is in excess of the energy required for melting is the lowest for air near the limit of cutting. The leading edges of the cut front for nitrogen show that in the absence of oxidation, the slope of the leading edge increases with cutting speed to meet the increasing demand on power for cutting with cutting speed. When air or oxygen is used as the plasma gas, the leading edge of cut front is nearly vertical for depths of up to $4 \mathrm{~mm}$, thus indicating the pronounced influence of oxidation for depths of up to approximately twice the arc diameter. For depths below $4 \mathrm{~mm}$, the influence of oxidation for kerf melting may be 2298 Influence of gas composition on plasma arc cutting of mild steel small, and the influence of plasma heating appears to be more important. The effect of different cutting speed and gas composition are shown in Figure 3. 




Nitrogen cutting

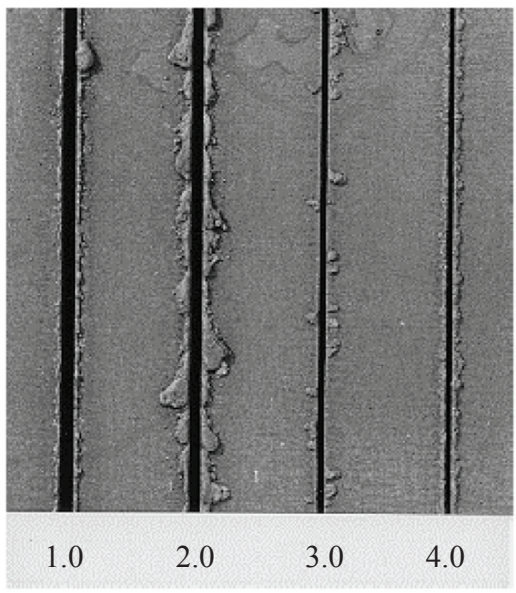

Air cutting

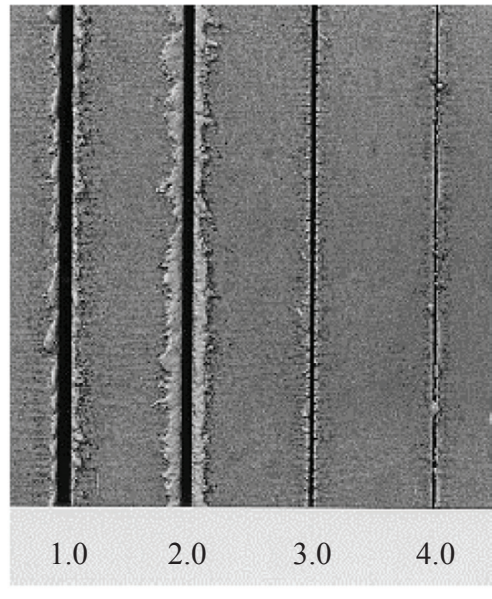

Oxygen cutting

FIGURE 3. Images of the bottom side of the $6 \mathrm{~mm}$ plate. Plate cut with nitrogen, air and oxygen at different cutting speeds (Ramakrishnan et al. (2000))

Nemchinsky (1998) proposed that Plasma flow inside the plasma arc chamber and the nozzle are modelled base on the latter. No artificial separation of the plasma column into two zones was made. However, existence of a sharp change between the hot center and cold envelope is confirmed by the calculation of the radial distribution of the plasma temperature inside the nozzle. In this way, two zone approximations are being provided.

Zajacet al. (2003) showed that thickness of the cold envelope diminishes downriver and becomes thinner at the nozzle exit. Conditions discussed above according to the Zajac et al. (2003) specifies that double arching is led by a possibility of electrical breakdown of the cold gas at the nozzle exit.

Gonzalez-Aguilar et al. (2005) calculated the temperature distribution and then compared with the experimental results from Pardo et al. (1999). Pardo et al. (1999) studied plasma temperature at the gap between nozzle and work piece. Moreover, calculated volt-ampere results were compared with the measured results thus, provided acceptable variations between results. Nevertheless, the anode is assumed as solid state anode and this condition prevents the plasma jet to flow through the metal plate. In other words, this condition is not representing realistic results for cutting process except maybe the initial phase of piercing in Zajac et al. (2003).More realistic assumption in the work-piece was made in Freton et al.(2001) and Freton et al. (2003) and anode was represented by a plate with a hole. Freton et al.(2001) and Freton et al. (2003) are included turbulence in their model.

The aim of the PAC process is heating, melting and removing material from the cut and there are only a few researchers focusing on this study. Swif-Hook (1973) conducted his study to heat conduction during the cutting. Beside, Swift - Hook et al. (1973) proposed a study including heat conduction in a metal plate heated by an infinity narrow line (line) heat source. Bunting and Cornfield (1975) studied calculation of the temperature distribution created through a moving cylinder that emits uniform heat. Nemchinsk et al.
(1997) created topical review of heat conduction of R433 by a moving cylinder uniformly emitting heat at its contact with the metal.

If air or oxygen is utilized to cut a steel, the plate needs to be heated with the heat coming from the chemical reaction of iron with oxygen. Related to approximations proposed in Teulet et al. 2006) and Ramakrishnan et al. (2000), this portion should be considerable and it is difficult to make precise estimations rather than rough estimations. This is because of the complexity of the kinetics of the chemical reactions of the oxygen and iron. Basically this chemical reaction is intensified by the increase in plasma jet speed. As the speed increases, the liquid layer thickness decreases. Nevertheless, plasma pressure inside the chamber is increased and relatively jet speed is increased to some degree only. After the material is heated and melted, in order to complete cutting process, it should be removed. A force, exerted on the molten metal should be robust to remove melt. Forces exerted to remove melt in the kerf are studied in Nemchinsky et al. (1996). It is resulted that surface tension and viscosity are the forces that slow the melt movement. Viscosity has no significant effect to thick plate cutting, whereas gravity plays essential role for cutting thick plates. While aerodynamic force is the critical factor in melt removal, minimum gas flow rate should be used to confirm that estimation. Nemchinsky et al. (2006) studied equation for minimum gas flow rate shown in eq. 2 .

$$
G_{\min }=\pi * R^{2} \sqrt{4 * \frac{\rho_{g}}{\pi * C_{t} * H} *\left(\gamma+\rho_{m} * \frac{\left(U^{3} * H^{2}\right)}{\alpha}\right)}
$$

Where;

$\mathrm{R}$ is the nozzle orifice radius, $\rho \mathrm{g}$ is gas density,

$\mathrm{H}$ is the plate thickness,

$\mathrm{U}$ is the cutting speed, $\gamma$ is the surface tension,

$C_{t}$ is the coefficient in expression of the drag force and 
$\alpha$ and $\rho \mathrm{m}$ are the thermal diffusivity and density of the molten metal.

Nemchinsky (2009) studied bevel angle which is one of the inaccuracy of the PAC related to the vertical walls. Due to the plasma flow, vertical walls never be straight and having bevel angle. The angle between angled vertical wall and straight vertical axis called as bevel angle. It is shown in the Figure 3. Bevel angle depend on the cutting speed. If the cutting speed is low, bevel angle is low, if cutting speed is high and then it is high. Basically, cutting condition is concurrence between productivity and cut quality. So that in order to increase the productivity, cut quality should be conceded. The schematic of the bevel angle is shown in the Figure 4.

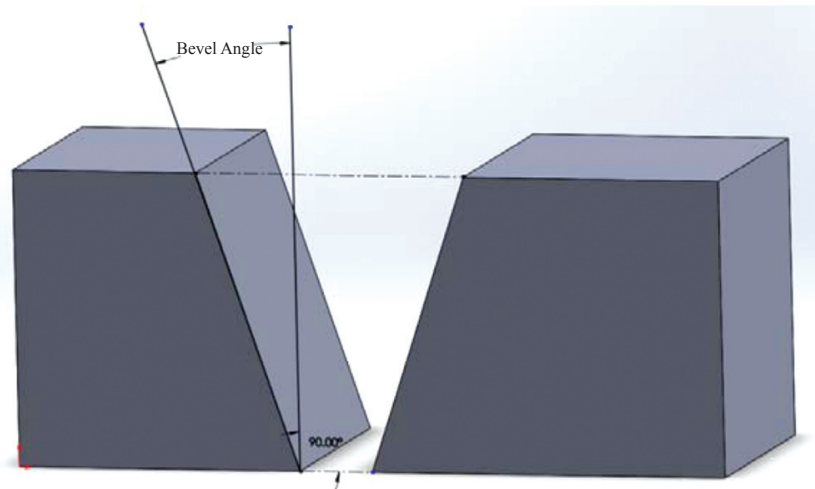

FIGURE 4. Bevel angle with respect to cutting speed

Nemchinsky (2009) highlighted another issue that is the plasma jet deflection in the vertical axis. The plasma plume is vertical or slightly bended ahead of the cut at low cutting speeds. As the cutting speed is increased, plasma jet is being deflected. If the speed increased more, then deflect is emerging from the bottom of the cut. At very high cutting speed, plasma jet does not reach the bottom of the plate, thus plasma jet is being deflected. Graph of bevel angle with respect to cutting speed are shown in the Figure 3.

Salonitis (2012) performed an experimental analysis of PAC and resulted that cutting edge, surface roughness, conicity and HAZ are essential parameters affecting cut quality of the PAC. Surface roughness during the cut is measured, $20 \mathrm{~mm}$ along a $150 \mathrm{~mm}$ length of the centerline in every specimen. Non steady state conditions applied at the beginning and at the end of the cut. Diamond tipped stylus surface measurement instrument (Mitutoyo SJ-400) used and specimen is observed and measured by an optical microscope (Leitz). The experimental results of the three quality characteristics selected for the evaluation that are cutting speed at the range of $1820 \mathrm{~mm} / \mathrm{min}$ and $2730 \mathrm{~mm} / \mathrm{min}$, cutting current at the range of $180 \mathrm{~A}$ and $240 \mathrm{~A}$ and the last characteristic is selected as cutting height at the range of $4.1 \mathrm{~mm}$ and $8.1 \mathrm{~mm}$. Based on these characteristics, Salonitis et al. (2012) observed that Surface roughness differs between $0.724 \mu \mathrm{m}$ and $1.178 \mu \mathrm{m}$, conicity differs between $7.43 \%$ and $11.84 \%$ and heat affected zone (HAZ) results differ between $350 \mu \mathrm{m}$ and $550 \mu \mathrm{m}$. The author of Salonitis (2012) reported that cutting height has the strongest effect on the quality characteristics especially on conicity and on the surface roughness of the cut.

Chamarthi et al. (2013) is studied investigation analysis of PAC parameters on unevenness surface of Hardox-400 material. In this study $12 \mathrm{~mm}$ plate thickness Hardox-400 has been cut by high tolerance voltage, cutting speed, and plasma gas flow rate included as main parameters in the analysis and their effect on unevenness of cut surface is evaluated. The design of experiments (DoE) techniques is used in order to outline the main parameters which define the geometry of the cut profile, as well as its constancy for Hardox-400 material plate. Despite the value selected for these parameters, the analysis shows that Hardox-400 plates can have different profiles, depending on the specific side considered. Unevenness can be obtained as a result of an experimental investigation aimed at selecting the proper values of process parameters of PAC system. Based on specific inputs, Unevenness optimized for better machining quality.

Bhuvenesh et al. (2012) stated that plasma arc cutter Selco Genesis 90 was used to cut Standard AISI 1017 Steel of $200 \mathrm{~mm}$ x100 mm x $6 \mathrm{~mm}$ manually based on specific parameters. The material removal rate (MRR) was measured by determining the weight of the specimens before and after the cutting process. The surface roughness (SR) analysis was conducted using Mitutoyo CS-3100 to determine the average roughness value $(\mathrm{Ra})$. Taguchi method was utilized to achieve optimum condition for both outputs studied. The microstructure analysis in the region of the cutting surface is performed using SEM. The results reveal that the SR values are inversely proportional to the MRR values. The quality of the surface roughness depends on the dross peak that occurred after the cutting process as shown in Figure 5.

Klimpel et al. (2017) studied the data analysis to determine the possibility to establish the field of operating values of laser and plasma arc cutting parameters for S355MC steel and S700MC steel with different thickness and grades in order to obtain the desirable class of cutting quality. A variety of approaches have been taken to carry out the preliminary analysis including rank correlation analysis, multidimensional data analysis and decision trees. Klimpel et al. (2017) carried out separately for each case of the selected materials. Basic parameters of laser beam and plasma arc cutting processes such as laser beam power (LBP), depth of focus (DoF), cutting speed (CS), assist gas pressure (AGP), current (C), torch standoff (TSO) and plasma gas flow rate (PGF) were considered as independent variables. On the other hand, the quality levels corresponding to geometrical features such as mean value of perpendicularity deflection (u), mean value of cut surface roughness (Rz5) and dross adherence (DA) were used as dependent variables.

Kechagias et al. (2017) studied thermal manufacturing processes for processing various electrical conducting materials such as carbon steel, stainless steel and experimentally investigates the influence of process parameters onto the dimensional accuracy performance of the plasma arc cutting process. The cutting parameters such as cutting speed $(\mathrm{mm} /$ 


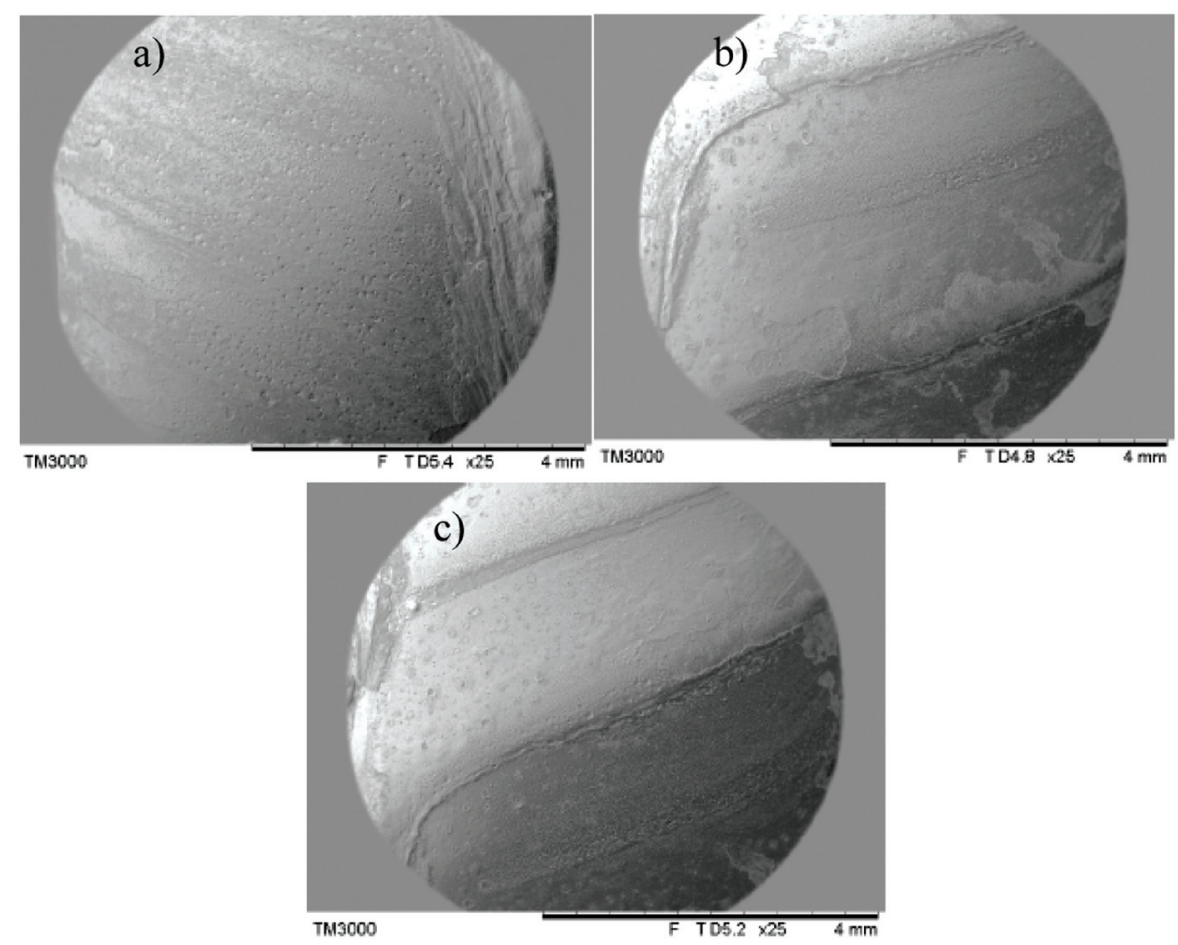

FIGURE 5. Structural cutting surface with different parameters from Bhuvenesh, R et al. (2012):a) $\mathrm{MRR}=5500-6400 \mathrm{~mm}^{3} / \mathrm{min}, \mathrm{SR}=$ $20-30 \mu \mathrm{m}$, b) $\left.\mathrm{MRR}=3600-4800 \mathrm{~mm}^{3} / \mathrm{min}, \mathrm{SR}=30-50 \mu \mathrm{m}, \mathrm{c}\right) \mathrm{MRR}=3000-3500 \mathrm{~mm}^{3} / \mathrm{min}, \mathrm{SR}=65-80 \mu \mathrm{m}$

min), torch standoff distance (mm), and arc voltage (volts) studied. Kechagias et al. (2017) also performed analysis of means (ANOM) and analysis of variances (ANOVA) for each process parameters in order for the effect of each parameter on the leaner dimensional accuracy to be assessed. The authors found that the cut edges indicates the plasma cutting gives consistently highest quality in terms of roughness but that laser cutting gives the highest class of perpendicularity. In addition, Very sharp bending tests observed the plasma arc and laser beam cut specimens indicted very high quality of straight cut edges of all specimens except laser cut specimens of steel plate grade S890Q with thickness $=15 \mathrm{~mm}$.

Balagenesh et al. (2017) investigated that the mild steel E250 plate of $6 \mathrm{~mm}$ thickness using Plasma Arc Cutting process by varying the parameters like current, cutting speed, arc height and pressure, thereby analyzing the roughness and hardness properties and machining time of the work piece cut to optimize the parameters. In this work of Plasma Arc Cutting (PAC) show the effect Speed ( $\mathrm{mm} / \mathrm{sec}$.), Current (A), Arc Height (mm), Pressure (bar) on E250 mild steel material. Balagenesh et al. (2017) carried out experiment by using Taguchi design methods and ANOVA analysis for Machining time, Hardness and Surface roughness by performing cuts of different run sets of $\mathrm{L}_{16}$ orthogonal Array. It is concluded that, in plasma arc cutting process there are various process parameters such as pressure, current, speed and arc height which affect cutting quality. By selecting the proper process parameters, following results can be achieved for proper cutting quality.
1. Hardness will be better for maximum pressure and arc height, medium current and speed.

2. Roughness will be better for maximum pressure and arc height, medium current and speed.

3. Machining time will be better for maximum pressure, current and arc height, medium speed.

\section{DISCUSSION}

According to the articles which have reviewed in the field of plasma arc cutting, various steel types are studied and process parameters of PAC were studied to find best characteristics during the cutting. Most commonly selected steel types are S235 mild steel, ASSAB DF3 steel, AISI 304 stainless steel, ST 50 carbon steel and SAILMA steel. However, Researchers are commonly focused on surface roughness, cutting speed, cutting current, standoff distance, conicity and thickness of cut but sill some parameters such as feed rate and edge roughness have not been fully elucidated. The DoE techniques such as ANOVA and Taguchi showed their importance to evaluate the impact of process parameters of PAC. Some researchers specifically investigated a single parameter individually to see its affect to machining characteristic of work piece. Whereas some of them combined more than one parameter to create optimized machining. In order to find optimal machining characteristics, most of the researchers conducted Taguchi technique or ANOVA analysis to their study. 
TABLE 1. Recent developments of PAC

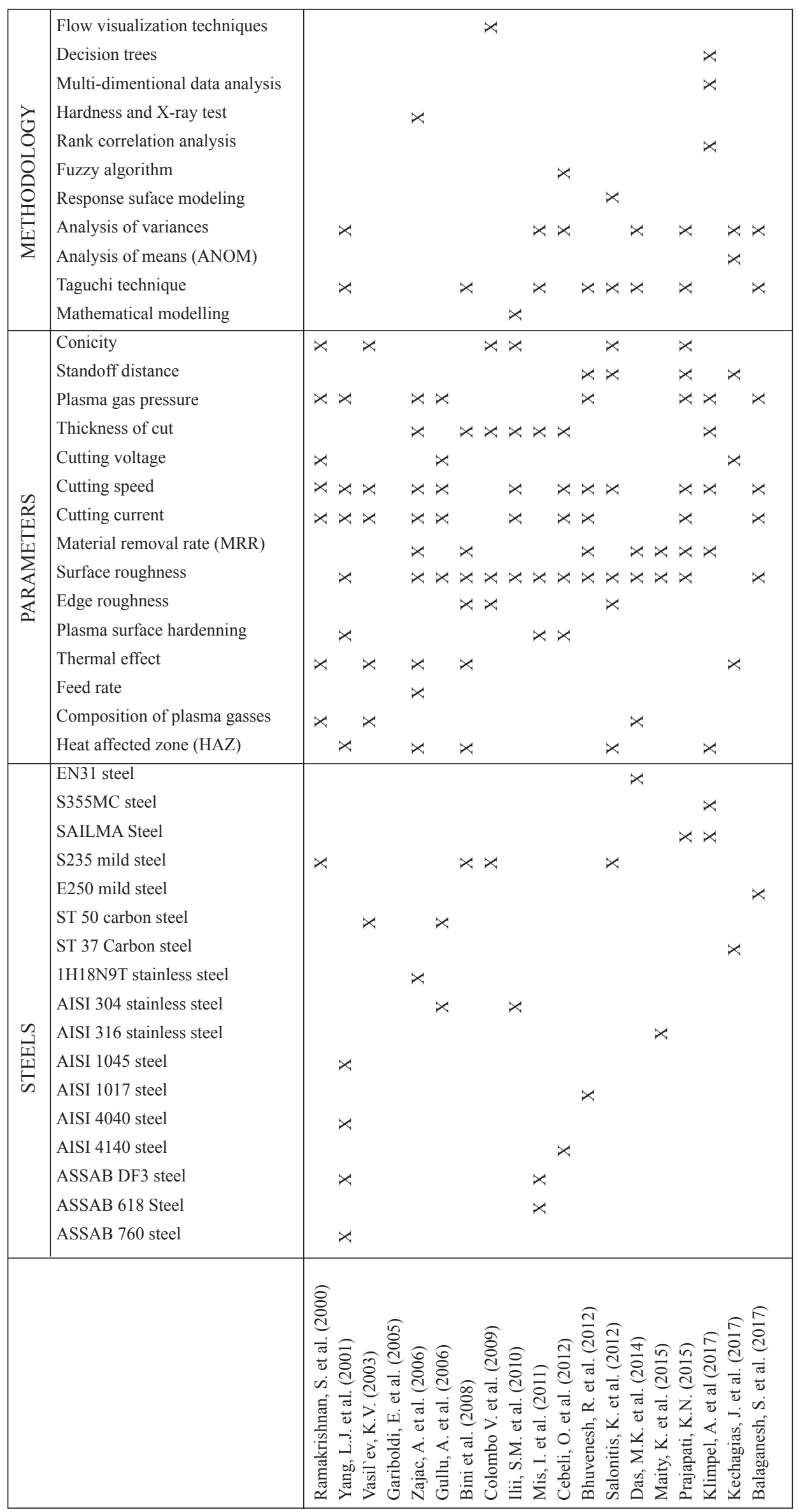




\section{CONCLUSION}

This paper presents a comprehensive review on the developments in analysis and optimization of PAC for Steel Alloys as well as a critical comparison of the process parameters involved and analyses methods used, aiming to let more experts know the current research status and also provide some guidance for future. There are many issues observed such as electrode erosion, bever angle, double arcing, surface properties and heat effects. However, those inaccuracies are not common for PAC processes only, they also occur in other cutting processes as well. From the tabular literature review, it can be seen that MRR, feed rate, surface roughness, plasma gas pressure, composition of gasses, cutting current, cutting voltage and cutting speed are major parameters affecting the PAC. However, less consideration was given the effect of feed rate and edge roughness on the machining characteristics. For the further research, it is recommended that there are variety speeds where the kerf differences are marked and plasma deflection is low. However, both effects are considerable, it is not well understood how to describe these effects at the same time. Very few researchers have worked on the mathematical modeling of the PAC process. Over the years, many techniques are applied to analyze PAC and its key parameters and their effects. Most researchers have applied Taguchi as the most common technique from 2000 to 2017; however there is still room for application of other DOE methods. Application of DOE can sufficiently help in estimating the main effects of the key parameters, addressing the influence of noise variables, generating Response surface models for optimization, and last but not the least, in reducing the number of experiments, thereby reducing the cost of experimentation.

\section{REFERENCES}

Tsiolikas. A., Kechagias. J., Salonitis K. \& Mastorakis, N. 2016. Optimization of cut surface quality during CNC Plasma Arc Cutting process. Int J Syst Appl Eng Dev10: 305-308.

Balaganesh, S., Dinesh, T., Kumar, B.D., Hariharan, S. \& Kumar, N.S. 2017. Experimental investigation on process parameters of E250 mild steel in plasma arc cutting. Int J Mod Trends Sci Technol, 3: 81-88.

Bemis, B. L. \& Settles, G. S. 1999. Ultraviolet imaging of the anode attachment in transferred-arc plasma cutting. IEEE Trans Plasma Sci 27(1): 44-45.

Benilov, M. S. \& Cunha, M. D. 2002. Heating of refractory cathodes by high-pressure arc plasmas: I. J Phys D: Appl Phys 35(1): 1736-1750.

Bhuvenesh, R., Norizaman, M. H. \& Abdul Manan, M.S. 2012. Surface roughness and MRR effect on manual plasma arc cutting machining. World Acad Sci Eng Technol 62(2): 503-506

Bini, R., Colosimo, B. M., Kutlu, A. E. \& Monno, M. 2008. Experimental study of the features of the kerf generated by a $200 \mathrm{~A}$ high tolerance plasma arc cutting system. J Mater Process Technol 196(1-3): 345-355.
Boselli, M., Ceschini, L., Colombo, V., Ghedini, E., Gherardi, M., Rotundo, F., Sanibondi, P., Dallavalle, S., Fazzioli, R. \& Vancini, M. 2009. Experimental investigation on the effects of the gas mixtures in plasma arc cutting of austenitic stainless steels. In: Proceedings ISPC 19, Bochum.

Bunting, K.A. \& Cornfield, G. 1975. Toward a general theory of cutting: a relationship between the incident power density and the cut speed. J Heat Transfer 97(1): 116-122

Chamarthi, S., Reddy, N. S., Elipey, M. K. \& Reddy, D. R. 2013. Investigation Analysis of Plasma arc cutting Parameters on the Unevenness surface of Hardox-400 material. Procedia Eng 64: 854-861.

Colombo, V., Concetti, A., Ghedini, E., Dallavalle, S. \& Vancini, M. 2009. High-speed imaging in plasma arc cutting: a review and new developments. Plasma Sour Sci Technol, 18(2): 1-24.

Das, M.K., Kumar, K., Barman, T. K. \& Sahoo, P. 2014. Optimization of process parameters in plasma arc cutting of EN 31 steel based on MRR and multiple roughness characteristics using grey relational analysis. Procedia Mater Sci 5: 1550-1559.

Fan, H.G. \& Kovacevic, R. 1999. Keyhole formation and collapse in plasma arc welding. J Phys D: Appl Phys 32(2): 2902-2909.

Freton, P., Gonzalez, J. J., Gleizes, A., Peyret, F. C., Caillibotte, G. \& Delzenne, M. 2001. Numerical and experimental study of a plasma cutting torch. $J$ Phys $D$ : Appl Phys 35(2): 115-131.

Freton, P., Gonzalez, J. J., Peyret, F. C. \& Gleizes, A. 2003. Complementary experimental and theoretical approaches to the determination of the plasma characteristics in a cutting plasma torch. $J$ Phys D: Appl Phys 36(11): 1269-1283.

Gariboldi, E. \& Previtali, B. 2005. High tolerance plasma arc cutting of commercially pure titanium. J Mater Process Technol 160(1): 77-89.

Gleizes, A., Gonzalez, J.J. \& Freton, P. 2005. Thermal plasma modelling. J Phys D: Appl Phys 38: R153-R183.

Gullu, A. \& Atici, U. 2006. Investigation of the effects of plasma arc parameters on the structure variation of AISI 304 and St 52 steels. Mater Des 27: 1157-1162.

Hsiao, Y.F., Tarng, Y.S. \& Huang, W.J. 2007. Optimization of Plasma Arc Welding Parameters by Using the Taguchi Method with the Grey Relational Analysis. Mater Manuf Processes 23: 51-58.

Ilii, S. M., Coteata, M. \& Munteanu, A. 2010. Experimental results concerning the variation of surface roughness parameter $(\mathrm{Ra})$ at plasma arc cutting of a stainless steel workpiece. Int J Mod Manuf Technol II(1): 31-36.

Ismail, M.I.S., Taha, Z. \& Hamdi, M. 2011. Experimental design and performance analysis in plasma arc surface hardening. World Acad Sci Eng Technol 56(8): 10521058.

Kechagias, J., Stavropoulos, P., Maropoulos, S. \& Salonitis, K. 2014. On the multi - paramenter optimization of 
CNC plasma-arc cutting process quality indicators using Taguchi Design of Experiments. Recent Adv Electr Eng 128-133.

Kadirgama, K., Noor, M. M., Harun, W. S. W. \& AboueEl-Hossein, K. A. 2010. Optimisation of heat affected zone by partial swarm optimisation in air plasma cutting operation. J Sci Ind Res 69(6): 439-443

Kechagias, J., Pappas, M., Karagiannis, S., Petropoulos, G., Iakovakis, V. \& Maropoulos, S. 2010. An ANN Approach on the Optimization of the Cutting Parameters During CNC Plasma-Arc Cutting. ASME 2010 10th Biennial Conference on Engineering Systems Design and Analysis 4: 643-649.

Kechagias, J., Petousis, M., Vidakis, N. \& Mastorakis, N. 2017. Plasma Arc Cutting Dimensional Accuracy Optimization employing the Parameter Design approach. ITM Web Conf. 9: 1-4.

Klimpel, A., Cholewa, W., Bannister, A., Luksa, K. \& Przystalka, P. 2017. Experimental investigations of the influence of laser beam and plasma arc cutting parameters on edge quality of high-strength low-alloy (HSLA) strips and plates. Int J Adv Manuf Technol 92(1-4): 699-713.

Maity, K. \& Bagal, D. 2015. Effect of process parameters on cut quality of stainless steel of plasma arc cutting using hybrid approach. Int $J$ Adv Manuf Technol 78(1-4): 161-175

Nemchinsky, V. 2002. Cathode erosion rate in high-pressure arcs: influence of swirling gas flow. IEEE Trans Plasma Sci 30(6): 2113-2116.

Nemchinsky, V. A. 1996. The effect of the type of plasma gas on current constriction at the molten tip of an arc electrode. J Phys D: Appl Phys 29(5): 1202-1208

Nemchinsky, V. A. 1997. Dross formation and heat transfer during plasma arc cutting. J Phys D: Appl Phys 30(18): 2566-2572

Nemchinsky, V. A. 1998. Plasma flow in a nozzle during plasma arc cutting. J Phys D: Appl Phys, 31(21): 31023107.

Nemchinsky, V. A. \& Severance, W. S. 2006. What we know and what we do not know about plasma arc cutting. J Phys D: Appl Phys 39(22): R423-R438

Nemchinsky, V. A. \& Severance, W. S. 2009. Plasma arc cutting: speed and cut quality. J Phys D: Appl Phys 42(19): 195204.

Nemchinsky, V. A. \& Showalter, M. S. 2003. Cathode erosion in high-current high-pressure arc. J Phys D: Appl Phys 36(6): 704-712.

Pandremenos, J., Salonitis, K. \& Chryssolouris, G. 2009. $\mathrm{CO} 2$ laser welding of AHSS.28th International Congress on Applications of Lasers and Electro-optics (ICALEO 09). 1507-1514

Paralikas, J., Salonitis, K. \& Chryssolouris, G. 2011. Investigation of the effect of roll forming pass design on main redundant deformations on profiles from AHSS. Int J Adv Manuf Technol 56(5-8): 475-491.
Pardo, C., González-Aguilar, J., Rodriguez-Yunta, A. \& Calderón, M. A. G. 1999. Spectroscopic analysis of an air plasma cutting torch. $J$ Phys D: Appl Phys 32(17): 2181-2189.

Phadke, S.M. 1989. Quality Engineering Using Robust Design. Prentice Hall.

Prasad, K.S. \& Bayya,T. 2017. Effect of pulsed current micro plasma arc parameters on weld bead geometry of AISI 316TI austenitic stainless steel. $J$ Mech Mech Eng 3(1): 56-65.

Radovanovic, M. \& Madic, M. 2011. Modelling the plasma arc cutting process using ann. Non-conventional Technol Rev 15: 43-48.

Ramakrishnan, S. \& Rogozinski, M. W. 1997. Properties of electric arc plasma for metal cutting. J Phys D: Appl Phys 30(4): 636-644.

Ramakrishnan, S., Gershenzon, M., Polivka, F., Kearney, T. N., \& Rogozinski, M. W., 1997. Plasma generation for the plasma cutting process. IEEE Trans Plasma Sci 25(5): 937-946.

Ramakrishnan, S., Shrinet, V., Polivka, F. B., Kearney, T. N. \& Koltun, P. 2000. Influence of gas composition on plasma arc cutting of mild steel. J Phys D: Appl Phys 33(18): 2288-2299.

Salonitis, K. \& Vatousianos, S. 2012. Experimental investigation of the plasma arc cutting process. Procedia CIRP 3: 287-292.

Stournaras, A., Stavropoulos, P., Salonitis, K. \& Chryssolouris, G. 2009. An investigation of quality in CO2 laser cutting of aluminum. CIRP J Manuf Sci Technol 2(1): 61-69.

Swif-Hook, D. T. \& Gick, A. E. F. 1973. Penetration welding with lasers-analytical study indicates that present laser beam welding capabilities may be extended tenfold. Weld Res Suppl 52: 492-499.

Teulet, P., Girard, L., Razafinimanana, M., Gleizes, A., Bertrand, P., Camy-Peyret, F. \& Richard, F. 2006. Experimental study of an oxygen plasma cutting torch: II. Arc-material interaction, energy transfer and anode attachment. J Phys D: Appl Phys 39(8): 1557-1573.

Urena, A., Otero, E., Utrilla, M.V. \& Munez, C.J. 2007. Weldability of a 2205 duplex stainless steel using plasma arc welding. J Mater Process Technol 182(1-3): 624-631.

Wang, J., Zhu, Z., He, C. \& Yang, F. 2011. Effect of dual swirling plasma arc cutting parameters on kerf characteristics. Int J Mater Form 4(1): 39-43.

Xu, W. J., Fang, J. C. \& Lu, Y. S., 2002. Study on ceramic cutting by plasma arc. J Mater Process Technol 129(1-3): 152-156.

Zajac, A. \& Pfeifer, T. 2006. Restricting the heat-affected zone during the plasma cutting of high-alloy steels. Weld Int. 20(1) 5-9.

Zhou, Q. Li, H., Liu, F., Guo, S., Guo, W. \& Xu, P. 2008. Effects of nozzle length and process parameters on highly constricted oxygen plasma cutting arc. Plasma Chem Plasma Process 28(6): 729-747. 
Zhou, X., Heberlein, J. \& Pfender, E. 1994. Theoretical study of factors influencing arc erosion of cathode. IEEE Trans Compon Packag Manuf Technol Part A 17(1): 107-112.

\section{Zeki Cinar}

Department of Mechanical Engineering,

Faculty of Engineering,

Eastern Mediterranean University,

North Cyprus, Gazimağusa, Mersin 10, Turkey

*Mohammed Asmael

Department of Mechanical Engineering,

Faculty of Engineering,

Eastern Mediterranean University,

North Cyprus, Gazimağusa, Mersin 10, Turkey

Qasim Zeeshan

Department of Mechanical Engineering,

Faculty of Engineering,

Eastern Mediterranean University,

North Cyprus, Gazimağusa, Mersin 10, Turkey

*Corresponding author; email:

mohammed.asmael@emu.edu.tr

Received date : $30^{\text {th }}$ October 2017

Accepted date : $20^{\text {th }}$ February 2018

In Press date : $1^{\text {st }}$ April 2018

Published date : $30^{\text {th }}$ April 2018 